\title{
Prevalence of overt and subclinical thyroid dysfunction among women and its effects on maternal and fetal outcome
}

\author{
Puja Kumari, Sadhana Singh*
}

Department of Obstetrics and Gynecology, N.M.C.H, Jamuhar, Bihar, India

Received: 11 April 2018

Accepted: 23 April 2018

*Correspondence:

Dr. Puja Kumari,

E-mail: drpujasingh55gmail.com

Copyright: (C) the author(s), publisher and licensee Medip Academy. This is an open-access article distributed under the terms of the Creative Commons Attribution Non-Commercial License, which permits unrestricted non-commercial use, distribution, and reproduction in any medium, provided the original work is properly cited.

\begin{abstract}
Background: Objective of present study was to determine the current prevalence of thyroid dysfunction in normal pregnant women and to study the impact of thyroid dysfunction on maternal and fetal outcome.

Methods: 400 pregnant women between 13 and 26 weeks of gestation were registered for the study. Apart from routine obstetrical investigations, TSH tests were done. Free T4 and anti-TPO antibody tests were done in patients with deranged TSH. Patients were followed up till delivery. Their obstetrical and perinatal outcomes were noted.

Results: The prevalence of hypothyroidism and hyperthyroidism was and $1.25 \%$, respectively. Adverse maternal effects in overt hypothyroidism included preeclampsia (16.6 vs. 7.8\%) and placental abruption (16.6 vs. $0.8 \%)$. Subclinical hypothyroidism was associated with preeclampsia (22.3 vs. $7.8 \%)$ as compared to the euthyroid patients. Adverse fetal outcome in overt hypothyroidism included spontaneous abortion (16.6 vs. 2.39\%), preterm birth (33.3 vs. $5.8 \%$ ), low birth weight (50 vs. $12.11 \%$ ), intrauterine growth retardation (25 vs. $4.9 \%$ ), and fetal death (16.6 vs.7\%) as compared to the euthyroid women. Adverse fetal outcomes in subclinical hypothyroidism included spontaneous abortion (5.5 vs. $2.39 \%$ ), preterm delivery (11.2 vs. 5.8\%), low birth weight (25 vs. 12.11\%), and intrauterine growth retardation (8.4 vs. $4.9 \%)$ as compared to the euthyroid women.

Conclusions: The prevalence of thyroid disorders was high in our study with associated adverse maternal and fetal outcomes. Routine screening of thyroid dysfunction is recommended to prevent adverse fetal and maternal outcome.
\end{abstract}

Keywords: Fetal outcome, Maternal outcome, Prevalence, Thyroid dysfunction

\section{INTRODUCTION}

Thyroid disorders constitute one of the most common endocrine disorders in pregnancy [1]. Pregnancy is associated with profound modifications in the regulation of thyroid function. These changes are the result of various factors like an increase of thyroxine-binding globulin (TBG) due to elevated estrogen and human chorionic gonadotropin (hCG), increased renal losses of iodine due to increased glomerular filtration rate, modifications in the peripheral metabolism of maternal thyroid hormones, and modification in iodine transfer to the placenta. ${ }^{2}$
The physiological changes of pregnancy can simulate thyroid disease. Symptoms of heat intolerance, sluggishness, fatigue, and constipation and examination findings of tachycardia, edema, and wide pulse pressure are common to pregnancy and thyroid disease much in same way. ${ }^{3}$ The prevalence of overt hyperthyroidism complicating pregnancy has been reported to range between 0.4 and $1.7 \%$ and an estimated $2-3 \%$ of women are hypothyroid during pregnancy.,4,5 Overt hyperthyroidism occurs in $0.4-1.7 \%$ of pregnant women. ${ }^{6}$

Women with thyroid dysfunction both overt and subclinical are at increased risk of pregnancy-related 
complications such as threatened abortion, preeclampsia, preterm labor, placental abruption, and postpartum hemorrhage. Fetal complications include low-birthweight babies, first-trimester spontaneous abortions, preterm delivery, fetal or neonatal hyperthyroidism, intrauterine growth retardation, high rates of still birth and neonatal deaths, neonatal hyperbilirubinemia, higher incidence of neonatal hypothyroidism, and increased perinatal mortality. ${ }^{7}$

There is a dearth of studies showing the prevalence of overt and subclinical thyroid dysfunction in pregnant women and its effect on the maternal and fetal outcomes; moreover, the few studies that were conducted were performed in foreign countries. Due to a paucity of information and studies on the Indian population, our study is a sincere effort to throw some light in this direction.

\section{METHODS}

The study was conducted in the department of obstetrics and gynaecology at Kasturba Hospital, between March 2012 and March 2013. The study was conducted after ethical clearance from the institutional ethical committee.

A total of 400 patients from Antenatal Clinics were included in the study. All healthy pregnant women with no other medical disorder, with singleton pregnancy between 13 and 26 weeks of gestation, were included in the study. Patients with multifetal gestation, known thyroid and metabolic disorder like diabetes, hypertension, and a history of pregnancy loss were excluded from the study. Apart from detailed history and examination, TSH was tested in all the patients enrolled in the study. In patients with deranged TSH, Free T4 and anti-TPO antibody tests were done. TSH was assayed by "Eliscan kit" using the principles of the sandwich Elisa. TPO antibody assay was done using the Elisa microwell kit (Cal biotech inc.), with the principal of indirect Elisa.

The reference range used in the study was based on guidelines of the American thyroid association 2011 for the diagnosis and management of thyroid disease during pregnancy and postpartum. ${ }^{8}$ According to the guideline, if trimester-specific reference range for TSH are not available in the laboratory, the following reference ranges are recommended: first trimester, $0.1-2.5 \mu \mathrm{IU} / \mathrm{ml}$; second trimester, $0.2-3.0 \mu \mathrm{IU} / \mathrm{ml}$; and third trimester, $0.3-3.0$ $\mu \mathrm{IU} / \mathrm{ml} .^{8}$

The patients with deranged thyroid dysfunction were treated and followed up till the termination of pregnancy. Those with abnormal tests were put on treatment, and thyroid function tests were repeated every 6 weeks during pregnancy and drug dosages titrated accordingly. Patients were followed up throughout pregnancy and monitored.

The maternal outcome was noted in terms of anemia, pregnancy-induced hypertension, abruption placenta, incidence of caesarean section, and postpartum hemorrhage.

The fetal outcome was noted in terms of birth weight, Apgar score at one and five minutes, neonatal intensive care unit admission, preterm delivery, intrauterine growth restriction, fetal distress, and intrauterine demise. Neonatal outcome was noted in terms of hyperbilirubinemia, respiratory distress, sepsis, hypoglycaemia, hypothermia, intracranial bleed, necrotizing enterocolitis, and early neonatal death.

Preeclampsia was defined as persistently elevated blood pressure (systolic $>140 \mathrm{mmHg}$ on more than 2 occasions) with proteinuria. Anemia was taken as a value of haemoglobin $<11 \mathrm{~g} \%$ in peripheral blood. Gestational diabetes screening was conducted at 24-28 weeks of gestation with $50 \mathrm{~g}$ of glucose intake (glucose challenge test). If the blood sugar value was $>140 \mathrm{mg} \%$ (blood plasma) or $>130 \mathrm{mg} \%$ (whole blood), then 100g GTT (glucose tolerance test), using the National Diabetes Data Group cutoff values, was carried out for diagnosis of gestational diabetes. ${ }^{9}$

Intrauterine growth restriction was defined as birth weight less than tenth percentile for gestational age. LBW was defined as weight equal to or $<2,500 \mathrm{gm}$. Preterm delivery as defined as delivery before 37 completed weeks. Low Apgar score considered if Apgar score at 1 min was $<7$.

\section{Statistical analysis}

All analyses were performed using the Statistical package of Social Sciences and Problem Solution (SPSS). Bilateral Fischer's exact test was used to compare two different rates if the number of measures in any one group was <5. Continuous variables were presented as mean \pm SD and analyzed using unpaired, two-tailed Student's t test. Analysis was done of the data obtained.

\section{RESULTS}

The patients were divided into the following groups according to thyroid function test results:

Group 1: Euthyroid, defined as normal TSH (0.2-

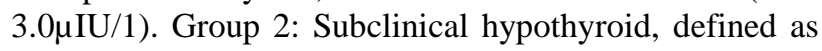
high TSH (>3.0 $0 \mu \mathrm{IU} / 1)$ in the presence of normal levels of Free T4 $(0.8-2.0 \mathrm{ng} / \mathrm{dl})$. Group 3: Overt hypothyroid, defined as high TSH $(>3.0 \mu \mathrm{IU} / 1)$ with low Free T4 $(<0.8$ ng/dl). Group 4: Subclinical hyperthyroid, defined as low serum TSH $(<0.2 \mu \mathrm{IU} / 1)$ concentration with normal Free T4 (0.8-2.0 ng/dl). Group 5: Overt hyperthyroid, defined as with high Free T4 $(>2.0 \mathrm{ng} / \mathrm{dl})$ with decreased $\mathrm{TSH}$ $(<0.2 \mu \mathrm{IU} / 1)$.

Out of 400 patients, $53(13.25 \%)$ had deranged thyroid function, making the prevalence of thyroid dysfunction $13.25 \%$. Prevalence of hypothyroidism was $12 \%$, out of 
which in 3\% had overt hypothyroidism and 9\% had subclinical hypothyroidism. The prevalence of hyperthyroidism was $1.25 \%$, out of which $0.50 \%$ had overt hyperthyroidism and $0.75 \%$ had subclinical hyperthyroidism in our study. Anti-TPO antibody was done in patients with deranged TSH levels. Ant-TPO antibody was found positive in $52 \%$ of hypothyroid patients. No anti-TPO antibody was found in hyperthyroid patients.

Table 1: Obstetrical variable in the antenatal period.

\begin{tabular}{|c|c|c|}
\hline Groups & Mean age & Mean BMI \\
\hline $\begin{array}{l}\text { Group } 1 \\
\text { Euthyroid N=347 }\end{array}$ & $24.56 \pm 3.733$ & $22.96 \pm 1.5$ \\
\hline $\begin{array}{l}\text { Group } 2 \\
\text { Subclinical hypothyroid } \\
\mathrm{N}=36\end{array}$ & $24.51 \pm 4.71$ & $23.37 \pm 1.4$ \\
\hline $\begin{array}{l}\text { Group } 3 \\
\text { Overt hypothyroid } \mathrm{N}=12\end{array}$ & $27.16 \pm 5.237 *$ & $24.58 \pm 1.31 *$ \\
\hline $\begin{array}{l}\text { Group } 4 \\
\text { Subclinical hypothyroid } \\
\mathrm{N}=3\end{array}$ & $26 \pm 1$ & $21.66 \pm 0.83$ \\
\hline $\begin{array}{l}\text { Group } 5 \\
\text { Overt hypothyroid N=2 }\end{array}$ & $30 \pm 0.70 *$ & $20 \pm 0.70 *$ \\
\hline
\end{tabular}

Maternal demographic characters are shown in Table 1. Maternal age was high in the overt hypothyroid and overt hyperthyroid groups. In our study, the mean BMI was $22.88 \pm 1.5$ for euthyroid patients, 23.17 \pm 1.5 for subclinical hypothyroid, $24.58 \pm 1.31$ for overt hypothyroid, 21.66 \pm 0.83 for subclinical hyperthyroid, and 20.5 \pm 0.70 for overt hyperthyroid. Obese women had higher TSH concentration and were prone to hypothyroidism than normal-weight women. No significant statistical difference was seen with respect to socioeconomic status and parity in different groups.

Thyroid dysfunction is associated with adverse maternal and fetal outcomes in pregnancy. The data on hypothyroidism were more conclusive than in hyperthyroidism as the sample size in the hyperthyroidism group was small and the disease is comparatively infrequent.

Table 2 show the maternal complications in different groups. Adverse maternal effects in overt hypothyroidism included preeclampsia (16.6 vs. $7.8 \%)$ and placental abruption (16.6 vs. $0.8 \%, \mathrm{P}=0.009)$. No significant increase in anemia ( 8.3 vs. $8.1 \%)$, gestational diabetes mellitus ( 8.3 vs. $0.58 \%)$, and postpartum hemorrhage $(8.3$ vs. $5.8 \%$ ) was seen in the overt hypothyroid group. Subclinical hypothyroidism was significantly associated with preeclampsia (16.6 vs. $7.8 \%)$ and placental abruption (16.6 vs. $0.8 \% . \mathrm{P}=0.009)$. No. Significant increase in anemia ( 8.3 vs. $8.1 \%$ ), gestational diabetes mellitus ( 8.3 vs. $0.58 \%$ ), and postpartum hemorrhage ( 8.3 vs. $5.8 \%$ ) was seen in the overt hypothyroid group. Subclinical hypothyroidism was significantly associated with preeclampsia (22.3 vs. $7.8 \%, \mathrm{P}=0.010)$ as compared to the euthyroid patients. No significant increase in anemia (14.1 vs. $8.1 \%$ ), placental abruption (0 vs. $0.8 \%), \mathrm{P}=0.010)$, gestational diabetes mellitus ( 0 vs. $0.58 \%$ ), and postpartum hemorrhage (5.5 vs. $5.8 \%$ ) was seen in the subclinical hypothyroid patients. There were no maternal deaths in any of the groups. No complications of myxedema coma and thyroid storm were seen in present study.

Table 2: Maternal complications in the study.

\begin{tabular}{|llllll|}
\hline $\begin{array}{l}\text { Maternal } \\
\text { Complications }\end{array}$ & Group 1 & Group 2 & Group 3 & Group 4 & Group 5 \\
\hline & Euthyroid & $\begin{array}{l}\text { Subclinical } \\
\text { hypothyroid }\end{array}$ & $\begin{array}{l}\text { Overt } \\
\text { hypothyroid }\end{array}$ & $\begin{array}{l}\text { Subclinical } \\
\text { hyperthyroid }\end{array}$ & $\begin{array}{l}\text { Overt } \\
\text { hyperthyroid }\end{array}$ \\
\hline Anemia & $\mathrm{N}=347$ & $\mathrm{~N}=36$ & $\mathrm{~N}=12$ & $\mathrm{~N}=3$ & $\mathrm{~N}=2$ \\
\hline Preeclampsia & $28(8.1)$ & $5(14.1)$ & $1(8.3)$ & 0 & 0 \\
\hline Abruption & $27(7.8)$ & $8(22.3)^{*}$ & $2(16.6)^{*}$ & 0 & 0 \\
\hline GDM & $3(0.87)$ & 0 & $(16.6)$ & 0 & $1(50)^{*}$ \\
\hline
\end{tabular}

PPH 20 (5.8) 2 (5.5) 1 (8.3) $00, * \mathrm{P} \leq 0.05$

Table 3: Mode of delivery in different groups $* \mathbf{P} \leq \mathbf{0 . 0 5}$.

\begin{tabular}{|llllll|}
\hline Mode of delivery & Group 1 & Group 2 & Group 3 & Group 4 & Group 5 \\
& Euthyroid & $\begin{array}{l}\text { Subclinical } \\
\text { hypothyroid }\end{array}$ & $\begin{array}{l}\text { Overt } \\
\text { hypothyroid }\end{array}$ & $\begin{array}{l}\text { Subclinical } \\
\text { hyperthyroid } \\
\text { Ovyperthyroid }\end{array}$ \\
\hline & $\mathrm{N}=347$ & $\mathrm{~N}=36$ & $\mathrm{~N}=12$ & $\mathrm{~N}=3$ & $\mathrm{~N}=2$ \\
\hline NVD & $275(79.3)$ & $28(78.0)$ & $5(41.6)$ & $3(100)$ & $1(50)$ \\
\hline LSCS & $59(17.1)$ & $6(16.6)$ & $5(41.6)^{*}$ & 0 & $1(50)$ \\
\hline LSCS for fetal distress & $8(13.5)$ & $2(33.3)$ & $3(60 \%)^{*}$ & 0 & 0 \\
\hline Instrumental delivery & $5(1.45)$ & 0 & 0 & 0 & 0 \\
\hline
\end{tabular}


Table 3 shows the route of delivery in different groups. $79.3 \%$ of euthyroid, $78 \%$ of subclinical hypothyroid, $41.6 \%$ of overt hypothyroid, $100 \%$ of subclinical hyperthyroid, and $50 \%$ of overt hyperthyroid patients had normal vaginal delivery. The rate of caesarean section was significantly higher in patients with overt hypothyroidism (41.6 vs. $17.1 \% \mathrm{P}=0.0031$ ) as compared to the euthyroid controls. No significant increase was seen in the subclinical hypothyroid and hyperthyroid groups.

Among the various indications of caesarean section, the most common was caesarean section for fetal distress (60\% in overt, $33.3 \%$ in subclinical, and $13.5 \%$ in overt hypothyroidism). The rate of caesarean section for fetal distress was statistically significant in overt hypothyroid patients (all other indications were equally distributed in all groups).

Fetal outcome in different groups is shown in Table 4. Adverse fetal outcomes in overt hypothyroidism included spontaneous abortion (16.6 vs. $2.39 \%, \mathrm{P}=0.054)$, preterm birth (33.3 vs. $5.8 \%, \mathrm{P}=0.04)$, low birth weight (50 vs. $12.11 \%)$, intrauterine growth retardation (25 vs. $4.9 \%, \mathrm{P}=0.02)$, and fetal death (16.6 vs. $1.7 \%, \mathrm{P}=$ $0.024)$ as compared to the euthyroid women. All of them were found to be highly significant. Adverse fetal outcomes in subclinical hypothyroidism included spontaneous abortion (5.5 vs. $2.39 \%$ ), preterm delivery (11.2 vs. $5.8 \%$ ), low birth weight (25 vs. $12.11 \%$ ), and intrauterine growth retardation (8.4 vs.4.9\%) as compared to the euthyroid women. Preterm birth was found to be statistically significant $(\mathrm{P}=0.02)$.

Table 4: Fetal outcomes in the study $* \mathbf{P} \leq \mathbf{0 . 0 5}$.

\begin{tabular}{|llllll|}
\hline Fetal outcome & Group 1 & $\begin{array}{l}\text { Group 2 } \\
\text { Subclinical } \\
\text { hypothyroid }\end{array}$ & $\begin{array}{l}\text { Group 3 } \\
\text { Overt } \\
\text { hypothyroid }\end{array}$ & $\begin{array}{l}\text { Group 4 } \\
\text { Subclinical } \\
\text { hypothyroid }\end{array}$ & $\begin{array}{l}\text { Group5 } \\
\text { Overt } \\
\text { hyperthyroid }\end{array}$ \\
\hline & $\mathrm{N}=347$ & $\mathrm{~N}=36$ & $\mathrm{~N}=12$ & $\mathrm{~N}=3$ & $\mathrm{~N}=2$ \\
\hline Live births & $34(94.4)$ & $333(96)$ & $8(66.6)$ & $3(100)$ & $2(100)$ \\
\hline Preterm birth & $9(25)^{*}$ & $20(5.8)$ & $4(33.3)^{*}$ & 0 & 0 \\
\hline IUGR & $3(8.4)$ & $17(4.9)$ & $3(25)^{*}$ & 0 & 0 \\
\hline LBW & $9(25)^{*}$ & $42(12.11)$ & $6(50)^{*}$ & 0 & 0 \\
\hline Abortions & $2(5.5)$ & $8(2.39)$ & $2(16.6)^{*}$ & 0 & 0 \\
\hline Still births & $6(1.7)$ & $2(16.6)^{*}$ & 0 & 0 & 0
\end{tabular}

Table 5: Neonatal outcome.

\begin{tabular}{|c|c|c|c|c|c|}
\hline Neonatal outcomes & Group 1 & Group 2 & Group 3 & Group 4 & Group 5 \\
\hline & Euthyroid & $\begin{array}{l}\text { Subclinical } \\
\text { hypothyroid }\end{array}$ & $\begin{array}{l}\text { Overt } \\
\text { hypothyroid }\end{array}$ & $\begin{array}{l}\text { Subclinical } \\
\text { hypothyroid }\end{array}$ & $\begin{array}{l}\text { Overt } \\
\text { hyperthyroid }\end{array}$ \\
\hline & $\mathrm{N}=333^{*}$ & $\mathrm{~N}=34^{*}$ & $\mathrm{~N}=8^{*}$ & $\mathrm{~N}=3 *$ & $\mathrm{~N}=2^{*}$ \\
\hline Hyper bilirubinemia & $20(6.1)$ & $4(11.8)$ & $2(25)$ & $1(33.3)$ & 0 \\
\hline Respiratory Distress Syndrome & $12(3.61)$ & $4(11.8)$ & $2(25)^{* *}$ & 0 & 0 \\
\hline Sepsis & $8(2.40)$ & $1(2.7)$ & $1(12.5)$ & 0 & 0 \\
\hline Hypoglycaemia & $3(0.9)$ & $1(2.7)$ & 0 & 0 & 0 \\
\hline Hypothermia & $2(0.6)$ & $1(2.7)$ & 0 & 0 & 0 \\
\hline Intracranial bleed & $2(0.3)$ & 0 & 0 & 0 & 0 \\
\hline Necrotising enterocolitis & $1(0.3)$ & 0 & 0 & 0 & 0 \\
\hline Early neonatal death & $4(1.2)$ & $1(2.7)$ & $1(12.5)$ & 0 & 0 \\
\hline
\end{tabular}

*Only live births in each group included

The mean birth weight in the group 1 was $2.61 \pm 0.45$, in group 2 was $2.58 \pm 0.7$, in group 3 was $2.2 \pm 0.8$, in group 4 was $2.9 \pm 0.3$, and in group 5 was $2.8 \pm 0.15$.

Mean birth weight in group 3 was significantly lower than that in Group $1(\mathrm{P}=0.0002)$. Mean birth weights in group 2, 4, and 5 were not statistically significant. Apgar score $<7$ at 1 min was seen in $37.5 \%$ of overt hypothyroid as compared to $5.4 \%$ of euthyroid neonates and was found to be statistically significant $(\mathrm{P}=0.0088)$. Neonatal outcome in different groups is shown in Table 5.

No significant difference was found in terms of NICU admission, Apgar score $<7$ at $5 \mathrm{~min}$, and neonatal complications needing admission to NICU, except respiratory distress syndrome which was seen significantly in patients with overt hypothyroidism (P $\leq 0.005)$. No other significant neonatal complications 
were seen in terms of hyperbilirubinemia, sepsis, hypoglycaemia, hypothermia, intracranial bleed, necrotizing enterocolitis, and early neonatal death in different groups.

\section{DISCUSSION}

It is best to screen women early in the pregnancy for thyroid dysfunction because thyroid diseases satisfy most of the criteria for a disease to warrant population screening. They are common, treatable, and to some extent preventable conditions which produce morbidity and pose special risks for pregnancy and the developing fetus. Screening for thyroid dysfunction in a woman who is pregnant or wants to be pregnant is important because thyroid hormone status is directly related to fetal brain development.

Prevalence of hypothyroidism was high in our study with $3 \%$ of overt and $9 \%$ of subclinical hypothyroid patients, thus necessitating the need for universal screening for thyroid dysfunction.

In present study, it was noted that overt hypothyroid and overt hyperthyroid women had higher maternal age as compared to women in the other groups. It was seen that increased maternal age was associated with higher incidence of thyoid dysfunction. The increase in prevalence of hypothyroidism in the older age group is due to current trend of older women becoming pregnant.

There were several important findings from study. First, preeclampsia was the most common maternal complication in hypothyroid patients followed by abruption. Second, the occurrence of fetal loss (spontaneous abortion, fetal death) was significantly increased in the pregnant women with overt hypothyroidism. Third, the pregnant women with subclinical and overt hypothyroidism had a significant increase in the incidence of preterm delivery, fetal distress, and intrauterine growth retardation.

Fetal loss was 16.6-fold greater in the pregnant women with overt hypothyroidism compared with those from the euthyroid group. Allan et al showed that TSH levels greater than $6 \mathrm{mU} / \mathrm{liter}$ were significantly associated with a higher frequency of stillbirth. ${ }^{10}$ Benhadi et al found that high maternal TSH levels were associated with an increased risk of pregnancy loss. ${ }^{11}$ Because TSH is inversely related to hCG levels, women with low hCG levels are at a greater risk of child loss.

In addition, maternal subclinical hypothyroidism increased the risk of fetal distress, which is in agreement with the study of Goel et al who reported a higher incidence of fetal distress in pregnancies complicated by maternal hypothyroidism (subclinical hypothyroidism, euthyroid on replacement therapy, and overt hypothyroidism); it has been suggested that hypothyroidism may exert irreversible effects on the fetus and placenta in early pregnancy, which impair their subsequent ability to tolerate stress, thereby increasing the incidence of fetal distress in labor. ${ }^{12}$ Fetal distress may impair infant developmental of the nervous system.

In another study, Sahu et al analyzed thyroid function during the second trimester in high-risk pregnant women and reported that prevalence of thyroid disorders, especially overt and subclinical hypothyroidism, was $6.47 \% .{ }^{13}$ Further, significant adverse effects on maternal and fetal outcome were seen emphasizing the importance of routine antenatal thyroid screening. In another study from India, the authors reported the prevalence of hypothyroidism and thyroid autoimmunity as 4.8 and $12.4 \%$, respectively.

Although hyperthyroidism in pregnancy is uncommon, effected on both the mother and child are critical. However, in this study, no significant finding was seen as the sample size was small and the disease is comparatively infrequent.

There were two main drawbacks in our study: first that TPO antibody levels were not examined in all the patients and second that neonatal cord blood TSH levels were not examined in patents.

The strong point of this study is that we included a large number of subjects in this study from India.

This study concludes that there is a high prevalence of hypothyroidism $(14.3 \%)$, the majority being subclinical in pregnant women, and universal screening of thyroid dysfunction may be desirable in our country.

Funding: No funding sources

Conflict of interest: None declared

Ethical approval: The study was approved by the Institutional Ethics Committee

\section{REFERENCES}

1. Abalovich M, Amino N, Barbour LA, Cobin RH, De Groot LJ, Glinoer D et al. Management of thyroid dysfunction during pregnancy and postpartum: an endocrine society clinical practice guideline. J Clin Endocrinol Metab. 2007; 92(8):1-47.

2. Negro R, Formoso G, Mangieri T, Pezzarossa A, Dazzi D, Hassan H. Levothyroxine treatment in euthyroid pregnant women with autoimmune thyroid disease: effects or, obstetrical complications. J Clin Endocrinol Metab. 2006;91:2587-91.

3. Sharma PP, Mukhopadhyay P, Mukhopadhyay A. Hypothyroidism in pregnancy. J Obstet Gynecol India. 2007;57:331-4.

4. Stagnaro-Green A. Overt hyperthyroidism and hypothyroidism during pregnancy. Clin Obstet Gynecol. 2011; 54(3):478-87.

5. Hollowell JG, Staehling NW, Flanders WD, Hannon WH, Gunter EW, Spencer CA, et al. Serum TSH, 
T(4), and thyroid antibodies in the United States population (1988-1994): National Health and Nutrition Examination Survey (NHANES III). J Clin Endocrinol Metab. 2002;87(2):489-99.

6. Glinoer D. Thyroid hyperfunction during pregnancy. Thyroid. 1998;8(9):859-64.

7. So LB, Mandel SJ. Thyroid disorders during pregnancy. Endocrinol Metab Clin North Am. 2006;35:117-36.

8. Stagnaro-Green A, Abalovich M, Alexander E, et al. Guidelines of the American Thyroid Association for the diagnosis and management of thyroid disease during pregnancy hypothyroidism in pregnancy and postpartum. Thyroid. 2011;21(10):1081-125.

9. American College of Obstetricians and Gynaecologists. Clinical American management guidelines for obstetrician-gynaecologists: gestational diabetes: ACOG Practice Bulletin No. 30. Obstet Gynecol. 2001; 98:525-38.

10. Allan WC, Haddow JE, Palomaki GE, Williams JR, Mitchell ML, Hermos RJ et al. Maternal thyroid deficiency and pregnancy complications: implications for population screening. J Med Screen. 2000;7:127-30.

11. Benhadi N, Wiersinga WM, Reitsma JB, Vrijkotte TG, Bonsel GJ. Higher maternal TSH level in pregnancy are associated with increased risk for miscarriage, fetal or neonatal death. Eur J Endocrinol. 2009; 160(6):985-91.

12. Goel P, Radotra A, Devi K, Malhotra S, Aggarwal A, Huria A. Maternal and perinatal outcome in pregnancy with hypothyroidism. Indian J Med Sci. 2005;59:116-7.

13. Sahu MT, Das V, Mittal S, Agarwal A, Sahu M. Overt and subclinical thyroid dysfunction among Indian pregnant women and its effect on maternal and fetal outcome. Arch Gynecol Obstet. 2010;281:215-20.

Cite this article as: Kumari $\mathrm{P}$, Singh $\mathrm{S}$. Prevalence of overt and subclinical thyroid dysfunction among women and its effects on maternal and fetal outcome. Int J Reprod Contracept Obstet Gynecol 2018;7:2123-8. 